\title{
Measurement of Resilience and the Time Value of Resilience
}

\author{
Timothy L.J. Ferris, Senior Member, IEEE
}

\begin{abstract}
In prior work a measure of resilience for use in systems design and management was presented. The measure has the form of a time integral of the system performance level. This form generates the research question: is time value of resilience a meaningful concept; like the time value of money in engineering economics. This paper presents four scenarios to explore the relationship of time and the value of resilience of a product or system. The scenarios are: perishable commodity packaging, the value of resilience rapidly diminishes after the contents' expiry; a consumer durable product for use in an evolving environment and interface requirement, where the value of resilience is related to the expiry of platform resilience capability; a national infrastructure asset where usage increases during the system life; and a factory, where the value of resilience depends on the obsolescence of the product. In the first two and last cases the value of resilience is high for a finite interval and then low or zero. In the third the value of resilience increases as the asset ages.
\end{abstract}

Index Terms-Measurement, system analysis and design, system metric, Systems system resilience, System lifecycle management

\section{INTRODUCTION}

$\mathrm{T}$ HIS paper extends the author's measure of resilience [1] by exploring a corollary question: is there a time value of resilience effect which should be included in the evaluation of system resilience? The prior work presented a resilience measure intended to help in making decisions about systems, both at design time and in through life management.

A system is the complete set of entities and relationships that provide a solution for a need. Thus, a system includes elements and provisioning for enablers as described in the UK MOD Defence Lines of Development, DLODs, the eight dimensions of: equipment, the technology that does the main task; personnel, the people who use and support the system; training, the training so the personnel have the right skills; logistics, to supply supporting materiel to the system; information, both to enable system function and for system support; infrastructure, to enable system support; organization, to use and to support the system; and a concept of use, to guide all system use.

Resilience is the systems engineering specialization based on recognition that systems are challenged both from within and without. Threats to system integrity and function may be addressed before encounter by pre-emptive or evasive action, at encounter by system robustness, and after encounter by managed system degradation and restorative action. The decision about what is appropriate for any system depends on the return on investment, in terms of improvement predicted using the measure of resilience in (1), as the tangible return on investment for implementation of means to provide resilience.

The measure of resilience presented in [1] is expressed:

$$
F O M=\sum_{i=1}^{n} \sum_{j=0}^{m-1}\left(w_{i k} \cdot v_{i k}\left(P_{i j}\right) \cdot\left(t_{j+1}-t_{j}\right)\right)
$$

where

$w_{i k}$ and $v_{i k}$ are the weight and value-for-scale, respectively, and $P_{i j}$ is the available performance in each dimension of performance, $i$, that apply during the interval $t_{j} \leq t<t_{j+1}$. Note that the $w_{i k}$ and $v_{i k}$ are values that apply under the system condition and operational environment conditions, $k$, which apply during the interval, allowing for the general case where performance required of a system may be dependent on circumstances, reflecting, for instance, need for 'full operational' or 'limp home' capability.

Equation (1) models the resilience scenario as an event driven discrete time system. The events lead either to available performance degradation, or partial or complete restoration, or management decisions to declare new performance expectations.

This approach to measurement of resilience differs from other measures of resilience in several key ways:

1. This measure is predictive.

2. Resilience is defined by comparing available performance at any time with the intended performance considered in design alternative tradespace analysis.

3. Resilience is treated as a life-cycle characteristic.

4. System resilience of each design or management alternative proposed can be compared.

5. The resilience of each alternative is described as a distribution of results predicted through Monte Carlo analysis of a large plurality of system life-cycles.

6. Alternatives are compared by statistical comparison of 
their distributions of resilience measure.

We observe that Equation (1) describes resilience in terms of achievable performance during a sequence of epochs, $t_{j} \leq t<$ $t_{j+1}$. These epochs are datable times through the system lifecycle, at times from the immediate future until retirement. There is an analogy of this time characteristic to the time characteristic in life cycle cost analysis, where cash flow events occur at datable future times. In life cycle costing each cash flow has a face value and a date, which are combined using time value of money, TVM, equations to calculate equivalent money value at a reference time, which is used to compare alternatives.

This characteristic of Equation (1) leads to this paper developing the concept of 'time value of resilience'.

\section{BACKGROUND PERSPECTIVES}

\section{A. Philosophical Foundation}

Resilience, in this work, builds on Heidegger's distinction of two modes of being: "pure being" and "process being" [2]. Pure being concerns the materiality of things and materials, and focuses on what is present and its properties. The properties include the physical parameters of performance of an entity. Process being concerns the capability afforded by an entity, and so views the entity as means to enable particular action.

Heidegger [3] illustrates the distinction between these two modes of being. Consider a hammer. If the hammer is in a fully usable condition, suitable for a carpenter to drive nails, then that hammer is a tool which can perform a function. The carpenter will interact with the hammer as process being, means to enable a task of value to the carpenter. But if the hammer is defective, and cannot be used to drive nails, it ceases to exist in the process being space, and becomes only pure being. The pure being hammer is a lump of stuff, but not useful for performing a task.

Products and systems are engineered to provide capability for their users, that is, to enable stakeholders to interact with them as process being, means for action. A resilience measure focused on the system as process being is useful for stakeholders who use it for its purpose. This reasoning led to Equation (1). This reasoning also suggests that over time the value of each performance dimension may vary, as a function of time, resulting in the overall value of resilience of the system varying with time depending on the extent to which stakeholders rely on the system performance.

\section{B. Previous Measures of Resilience}

In [1] a number of sources, listed in Appendix A, were discussed in relation to development of Equation (1). These measures view disruptions as discrete events resulting in loss of system performance and an interval before the system achieves a new steady state performance. The new steady state performance may be complete restoration or some other, often lower, value of performance. These measures include time, but only as the interval between event and recovery or the new steady state. This event triggered origin of the time scale results in all calendar times being regarded as equivalent.

These previous measures of resilience consider the system at the level of focus on the system itself. This approach focuses on the materiality of the system and the properties of that materiality, that is, things at Heidegger's pure being.

The approach taken in [1], using the weight and value-forscale terms, follows the decision analysis method used in systems engineering for trade-off between design alternatives. It focuses on the desirability of the system performance for achieving the objective of the system. The trade-off analysis views the analysis space as a static matter of which alternative provides the best satisfaction of the balance of objective measures of the system.

The difference between the conventional decision analysis method and the measurement of resilience in [1] is that in the latter the measure is determined through Monte Carlo analysis of a high plurality of system life-cycles for each alternative.

Thus [1] presented a resilience measure regarding the system as Heidegger's process being, as having been brought into being as means to provide an effect in the world.

\section{Time Value of Money}

The time value of money, TVM, is a well-established concept and one of the theoretical foundations of engineering economics. All engineering economics textbooks, for example [4] and [5], introduce the concept of TVM. The fundamental relationship in TVM is that any future payment, $P_{j}$, can be transformed to an equivalent payment at the present time, $P_{0}$, using Equation (2).

$P_{0}=\frac{P_{j}}{(1+i)^{j}}$

The transformation depends on an interest rate, $i$, which is compounded over a series of $j$ interest payment intervals. The assumption which underlying this analysis is that an investment in something, for example to acquire an asset which generates a series of future revenue payments must be compared with the return that would have been earned by compound interest deposit.

Consider a set of cash flow events, representing an initial investment and a set of net revenue values received through the asset life, Fig 1. The question is whether a particular projected cash flow amounts would result in a better return than could be achieved through a cash deposit. Using the variable definitions in Fig 1, and for interest rate $i$, the equivalent present value is given by equation (3):

$\mathrm{PV}=\sum_{j=0}^{n} \frac{P_{j}}{(1+i)^{j}}$

\section{Time Value and Resilience}

Equations (1) and (3) have the form, equation (4):

Output_Value $=$ $\sum_{j=0}^{n}($ Value_of_Something).(Time_factor)

In the case of TVM the time factor is clear, the $\frac{1}{(1+i)^{j}}$ term. In equation (1) the time factor is not obvious but could be 


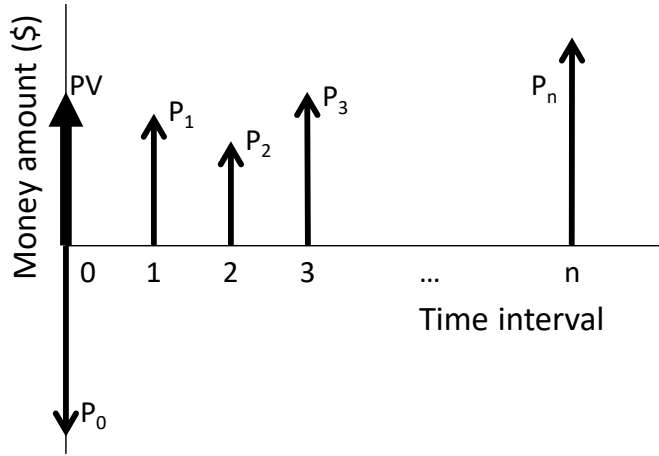

Fig. 1. Graphical definition of the terms in equation (3), the amount and timing of periodic payments and the Present Value.

introduced in two places. The weight of the dimension of measure factors $w_{i k}$ may be functions of time, reflecting change in the relative weighting of the dimensions of measure through time. Also, the value for scale functions, $v_{i k}\left(P_{i j}\right)$, could vary with time, reflecting change in the value to stakeholders of magnitudes of the dimensions of measure through time.

This paper presents an initial investigation of this issue with respect to four scenarios.

A Scopus search for terms < Resilience AND "time value" > in the article title, abstract or keyword fields was conducted. This identified three items, as follows.

1) Budogo, Mnyone and Juma [6] investigated the effect of land use reallocation involving displacement of a poor community. Their use of "resilience" concerned the comparison of the state of the community before and after displacement, and "time value" referred to the TVM aspect of the compensation paid to the displaced. This work is not relevant to the present subject.

2) Espinoza and Rojo [7] discuss limitations of the traditional TVM, net present value (NPV), analysis of long-term projects, such as mines. A challenge is that far future cash flows are so discounted, particularly when using constant and higher risk adjusted discount rates (RADR), that risks related to far future events are poorly reflected. They used "resilience" to refer to response to future risk events and "time value" in the sense of Equation (3). They present a method of determining what they argue to be a more realistic, risk cognizant, project NPV. Espinoza and Morris [8] extended this work to address the problem of reclamation and post-reclamation costs in mining. This work shows that the current cost of a cessation of service of a system depends on both the circumstances and the date of the retirement from service. This work is not relevant to the present paper.

3) The idea of a relationship between resilience and time is discussed in [9]. In this work "resilience" is a material property of wood, the subject matter of the investigation. "Time" was concerned with duration of one part of the wood treatment. This work is not relevant to the present investigation.

\section{SCENARIO DESCRIPTIONS}

We present four system scenarios to show that the concept of time value of resilience would lead to different desirable resilience characteristics which, in turn, would be expressed in significantly different resilience related requirements on the products or systems. These cases are developed simply, with enough detail to illustrate the time value of resilience concept, and to show that the scaling of the value of resilience with respect to time is different for different system types.

\section{A. System Scenario 1 - Single-use Retail Food Packaging}

\section{1) Description}

We consider the resilience of a single-use retail food packing item, such as a milk container. In the event of failure the contents are lost, a low direct cost, but, depending on where the failure occurs, such as milk spilled in a car and impregnating upholstery, consequential loses may be much higher.

2) Single-use Food Package Manifestation of Resilience

The food content of the package has a finite shelf-life, $T$ days. It is valuable to all stakeholders to have a package which will last, withstanding all normal stresses imposed on it, for $T+x$ days, where $x$ is a margin to allow for the expired food to remain in storage because package failure that spills expired contents would have significant consequential cost. The financial value of the resilience during the pre-expiry interval, that is for time, $t$, such that $t<T$ is $\$ V+\$ C$ where $\$ V$ is the value of the food content of the package, and $\$ C$ is the value of consequential effects of package failure. For $T \leq t \leq T+x$ the value of resilience of the package is $\$ C$. For $t>T+x$ the value of resilience declines significantly because product stock management results in its removal from any place where failure would have disadvantageous consequential effects.

The time characteristic of resilience in this case suggests design criteria, which would be transformed into formal statements of requirement to determine design, as follows:

1) The package must contain the product, without loss or leakage, and any security features included in the package must provide true status indication for interval $0 \leq t \leq T$.

2) The package must contain the product, without loss or leakage, for interval $T \leq t \leq T+x$. Ideally, the package would make the contents appear unusable during this interval.

3) No specific performance is required of the package for the interval $T+x<t$. A package which changes the content to reduce possible consequential damage, such as turning the milk into jelly to not contaminate anything is desirable.

4) If either of the desirable conditions in 2 and 3, above, were included as package requirements, the package resilience assessment must include the reliability of that function.

\section{B. System Scenario 2 - Mobile Phone}

\section{1) Description}

A mobile phone is a terminal device in a public access communications system which allows customers to bring their own device to use a service provided by a telecommunications provider. The consumer invests to have their choice of terminal device which can access the service provider's network by 
having compatibility with agreed service provider standards.

This contrasts with a closed network where the investor provides both the network and all the terminal devices, such as a military communications network. Where a single owner communications system is acquired with very long intended life, for example decades, in the commercial network the service providers change technology standards relatively frequently (consider mobile network changes from Analog, to $2 \mathrm{G}, 3 \mathrm{G}, 4 \mathrm{G}$ and now 5G) with old handsets providing limitation of functionality, compared with the network, or even continuity of connectivity. The result is that a retail customer perceives little value in a terminal device with physical resilience to be operable for an extended life of, for example, 20-40 years.

\section{2) Mobile Phone Manifestation of Resilience}

A mobile phone terminal device has a role in people's life captured in its Japanese name keitai, "the thing you must have with you" [10], as a device which is used virtually 24/7 and has a part in many life activities. Therefore, it must be reliable on the time scale of day-by-day usage. But, it is also recognized that over time the range of services a user wants to have supported will increase. In addition, the device itself is a fashion statement item, so after a certain usage window many users will want to replace their device.

For most users, most of the time, handset failure is an inconvenience, so the value of capacity to withstand destructive events beyond day-to-day mishaps is reasonably low. Recognizing the device fragility most users obtain a separate case, also a fashion item, to provide external ruggedizing protection. For major incidents, most owners accept device failure is likely, and until a certain device age significant repairs may be commissioned. The author has seen phones with shattered screens resulting from motor vehicle roll-overs, which were still usable, at least for the several months the owner was in hospital and unable to organize repair or replacement.

Another factor which informs us about the time value of resilience in mobile phone design is the projected second-hand value of the phone at future dates. We note the simplification that the value of resilience of the phone is here reduced to just a financial matter. This is a simplification which allows use of publicly available data and avoids the complication of determining value in the unusual cases of simultaneous phone failure and high consequence need to use it.

To develop this scenario we use data for pricing, release dates and trade-in values of iPhones. Two sources have been used:

1) The Apple website [11], and its internal links for new product pricing and trade-in value of earlier models; and

2) The History Cooperative [12] for release dates and historic new prices for 'base' versions of each model.

The results are presented in Table I. In Table II the data is transformed to determine the implied depreciation in dollar value, and then in compounded interest rate over the age of the device. Table II shows that the lowest implied depreciation rate occurs when a 4-year-old model is traded-in. The much higher depreciation rate for the 3-year-old model reflects the unattractiveness of a reasonably new but pre-owned asset, particularly of a kind which is a combination of functional tool and fashion item. The secondhand end-user market is unwilling to pay the premium price that a new sample commands, particularly as new samples are still available at the original
TABLE I

IPHONE HISTORIC PRICING AND CURRENT UPGRADE PRICING (USING [37] AND

\begin{tabular}{lllll}
\hline \multicolumn{5}{c}{$[38])$} \\
& & & $\begin{array}{l}\text { XR 64G } \\
\$ 749\end{array}$ & $\begin{array}{l}\text { XS 64G } \\
\$ 999\end{array}$ \\
\hline \hline $\begin{array}{l}\text { Product } \\
\text { Model }\end{array}$ & Release & $\begin{array}{l}\text { Original } \\
\text { Date }\end{array}$ & $\begin{array}{l}\text { Price to } \\
\text { Upgrade }\end{array}$ & $\begin{array}{l}\text { Price to } \\
\text { Upgrade }\end{array}$ \\
\hline $7+$ & $16 / 9 / 2016$ & n $/ \mathrm{a}$ & $\$ 479$ & $\$ 729$ \\
7 & $16 / 9 / 2016$ & $\$ 449$ & $\$ 549$ & $\$ 799$ \\
$6 s+$ & $25 / 9 / 2015$ & $\$ 299$ & $\$ 549$ & $\$ 799$ \\
$6 \mathrm{~s}$ & $25 / 9 / 2015$ & $\$ 199$ & $\$ 599$ & $\$ 849$ \\
$6+$ & $19 / 9 / 2014$ & $\$ 299$ & $\$ 599$ & $\$ 849$ \\
6 & $19 / 9 / 2014$ & $\$ 149$ & $\$ 649$ & $\$ 899$ \\
\hline \hline
\end{tabular}

TABLE II

IPHONE TRADE-IN VALUE IMPLIED DEPRECIATION IN DOLLAR AMOUNT AND DEPRECIATION RATE (USING [37] AND [38])

\begin{tabular}{|c|c|c|c|c|}
\hline & & & $\begin{array}{l}\text { XR 64G } \\
\$ 749\end{array}$ & $\begin{array}{l}\text { XS 64G } \\
\$ 999\end{array}$ \\
\hline $\begin{array}{c}\text { Product } \\
\text { Model }\end{array}$ & $\begin{array}{l}\text { Number } \\
\text { of Years }\end{array}$ & $\begin{array}{l}\text { Original } \\
\text { Price }\end{array}$ & Depreciation & Depreciation \\
\hline 7 & 3 & $\$ 449$ & $\begin{array}{l}\$ 249 \\
(31.0 \%)\end{array}$ & $\begin{array}{l}\$ 249 \\
31.0(\%)\end{array}$ \\
\hline $6 s+$ & 4 & $\$ 299$ & $\begin{array}{l}\$ 99 \\
(10.5 \%)\end{array}$ & $\begin{array}{l}\$ 99 \\
(10.5 \%)\end{array}$ \\
\hline $6 s$ & 4 & $\$ 199$ & $\begin{array}{l}\$ 49 \\
(7.3 \%)\end{array}$ & $\begin{array}{l}\$ 49 \\
(7.3 \%)\end{array}$ \\
\hline $6+$ & 5 & $\$ 299$ & $\begin{array}{l}\$ 149 \\
(14.7 \%)\end{array}$ & $\begin{array}{l}\$ 149 \\
(14.7 \%)\end{array}$ \\
\hline 6 & 5 & $\$ 149$ & $\begin{array}{l}\$ 99 \\
(14.8 \%)\end{array}$ & $\begin{array}{l}\$ 99 \\
(14.8 \%)\end{array}$ \\
\hline
\end{tabular}

price. The increasing depreciation of the 5-year-old model reflects components associated with physical wear-out of the asset instance, either from accumulation of minor trauma or time and use related product degradation, and the effect of the advance toward obsolescence, for example related to the memory capacity, affecting the apps that can be loaded and used, or changes in the communications standards, currently the introduction of $5 \mathrm{G}$ services. These effects are named mission resilience and platform resilience, respectively by Small et al [13]. These factors affect the trade-in value because they influence the price a secondhand buyer is willing to pay because of the expected useful lifespan beyond the date of that secondhand purchase.

In the mobile phone handset scenario the value of product mission resilience is reasonably high for typical day-to-day use duration needs. The phone's has high capacity to function when subjected to the various traumas common during use, and possibly after serious events, for a reasonable expected life.

The trade-in values reflect the platform resilience value that new phone buyers seek from the product. Beyond the first owner lifespan, if the phone has platform resilience that extends to the time when the secondary buyer would use it, it has reasonable trade-in value for the original owner. If the mission resilience was significantly extended the phone would end life because of a platform resilience related issue, such as a change of network standards. There is no value to the buyer of the phone to pay the large premium which would be required to achieve mission resilience that extends beyond environment changes that make the product obsolete. 
Similarly, there is no value to consumers to pay the very high premium that would be required to enable platform resilience which would enable conversion to suit a new network standard, given that even if such conversions were possible, most consumers would not want to invest a high proportion of the initial purchase price of a phone handset and end up with a legacy product which has been updated. Most would prefer to buy a totally new handset.

This scenario is relevant to design of products and systems which provide an enduring service, and the service is delivered in a changing environment, but where the nature of the system does not demand that the same physical thing provide the service for the entire duration of service provision.

\section{System Scenario 3 -Dartford Crossing (East of London)}

\section{1) Description}

The third scenario is an element of transport infrastructure which provides a road link between two places separated by features that prevent any travel via an almost adjacent route. We consider the Dartford Crossing of the Thames estuary east of London. This crossing provides the link between the eastern extremities of the M25 motorway, to the north and south.

Background information relevant to this analysis is available in Wikipedia [14]. The crossing was constructed in three stages:

1) The first tunnel in 1963;

2) The second tunnel in 1980; and

3) The bridge in 1991.

If the Dartford Crossing is closed the nearest other crossings are the Woolwich Ferry, 9 miles upstream and 24 miles road journey, the Blackwall Tunnel, 12 miles upstream and 27 miles road journey, and, for vehicles higher than 16.5 feet, a circuit of the M25 around London, 124 miles road journey. All distances quoted are based on a journey from the A13/A282 intersection to the A2/A282 intersection, a distance of 5.5 miles by the direct Dartford Crossing route, using GoogleMaps. The additional journeys involve additional road travel, and therefore cost of operation of vehicles, significant delay which also will increase congestion and delays for all road network users in the affected regions and other consequent effects, including pollution, and economic costs of transport delays.

Closure of the crossing results in resource consumption, and opportunity cost, of increasing real value per vehicle of each vehicle type, because the greater baseline usage of alternate routes results in longer delays, increased consequent effects, resulting from the increased congestion of forcing the alternative road routes to operate at higher loads when they are already operating close to capacity. Therefore, our evaluation of the value of resilience can consider the amount of traffic impacted by closure as a proxy for the value of the resilience of the crossing as a function of time with the cost, per vehicle increasing at a rate greater than 1:1.

\section{2) Dartford Crossing Manifestation of Resilience}

We present data for the amount of traffic using the Dartford Crossing for the interval 1964 to 2014, the compounding increase in traffic flow based on design expectation for the first year and actual use in that year in Table III [15].

Table III shows that the original design usage expectation was exceeded in the first year with usage nearly three times expectation. Thereafter the crossing has had use growth to over
TABLE III

DARTFORD CROSSING ANNUAL TRAFFIC FLOW (USING [41])

\begin{tabular}{|c|c|c|c|c|}
\hline Date & $\begin{array}{l}\text { Total } \\
\text { vehicles }\end{array}$ & $\begin{array}{l}\text { Years } \\
\text { into } \\
\text { Life }\end{array}$ & $\begin{array}{l}\text { Compound } \\
\text { use growth } \\
\text { on design } \\
(\%)\end{array}$ & $\begin{array}{l}\text { Compound use } \\
\text { growth on } \\
\text { initial }(\%)\end{array}$ \\
\hline $\begin{array}{l}\text { Design } \\
\text { expectation } \\
1964 / 1965\end{array}$ & $2,000,000$ & & & \\
\hline $1964 / 1965$ & $5,829,879$ & 0 & & \\
\hline $1965 / 1969$ & No data & & & \\
\hline $1969 / 1970$ & $8,000,000$ & 5 & $31.95 \%$ & $6.53 \%$ \\
\hline $1970 / 1980$ & No data & & & \\
\hline 1980/1981 & $11,447,743$ & 16 & $11.52 \%$ & $4.31 \%$ \\
\hline 1981/1982 & $12,055,493$ & 17 & $11.15 \%$ & $4.37 \%$ \\
\hline $1982 / 1983$ & $13,855,044$ & 18 & $11.35 \%$ & $4.93 \%$ \\
\hline $1983 / 1984$ & $18,727,648$ & 19 & $12.49 \%$ & $6.33 \%$ \\
\hline $1984 / 1985$ & $20,988,944$ & 20 & $12.47 \%$ & $6.61 \%$ \\
\hline $1985 / 1986$ & $23,708,978$ & 21 & $12.50 \%$ & $6.91 \%$ \\
\hline $1986 / 1987$ & $26,229,816$ & 22 & $12.41 \%$ & $7.07 \%$ \\
\hline $1987 / 1988$ & $28,483,178$ & 23 & $12.24 \%$ & $7.14 \%$ \\
\hline $1988 / 1989$ & $29,736,544$ & 24 & $11.90 \%$ & $7.02 \%$ \\
\hline $1989 / 1990$ & $30,386,390$ & 25 & $11.50 \%$ & $6.83 \%$ \\
\hline 1990/1991 & $29,360,644$ & 26 & $10.89 \%$ & $6.42 \%$ \\
\hline $1991 / 1992$ & $34,797,684$ & 27 & $11.16 \%$ & $6.84 \%$ \\
\hline $1992 / 1993$ & $37,385,483$ & 28 & $11.02 \%$ & $6.86 \%$ \\
\hline $1993 / 1994$ & $39,947,382$ & 29 & $10.88 \%$ & $6.86 \%$ \\
\hline $1994 / 1995$ & $42,557,309$ & 30 & $10.73 \%$ & $6.85 \%$ \\
\hline $1995 / 1996$ & $44,363,898$ & 31 & $10.51 \%$ & $6.77 \%$ \\
\hline $1996 / 1997$ & $46,403,105$ & 32 & $10.32 \%$ & $6.70 \%$ \\
\hline $1997 / 1998$ & $48,455,901$ & 33 & $10.14 \%$ & $6.63 \%$ \\
\hline 1998/1999 & $50,420,231$ & 34 & $9.96 \%$ & $6.55 \%$ \\
\hline $1999 / 2000$ & $50,284,079$ & 35 & $9.65 \%$ & $6.35 \%$ \\
\hline $2000 / 2001$ & $50,919,256$ & 36 & $9.41 \%$ & $6.21 \%$ \\
\hline $2001 / 2002$ & $52,040,197$ & 37 & $9.21 \%$ & $6.09 \%$ \\
\hline $2002 / 2003$ & $53,047,137$ & 38 & $9.01 \%$ & $5.98 \%$ \\
\hline $2003 / 2004$ & $53,889,168$ & 39 & $8.81 \%$ & $5.87 \%$ \\
\hline $2004 / 2005$ & $54,363,607$ & 40 & $8.61 \%$ & $5.74 \%$ \\
\hline $2005 / 2006$ & $54,480,560$ & 41 & $8.39 \%$ & $5.60 \%$ \\
\hline $2006 / 2007$ & $53,619,224$ & 42 & $8.15 \%$ & $5.43 \%$ \\
\hline $2007 / 2008$ & $53,240,629$ & 43 & $7.93 \%$ & $5.28 \%$ \\
\hline $2008 / 2009$ & $51,662,878$ & 44 & $7.67 \%$ & $5.08 \%$ \\
\hline $2009 / 2010$ & $51,247,772$ & 45 & $7.47 \%$ & $4.95 \%$ \\
\hline 2010/2011 & $50,939,941$ & 46 & $7.29 \%$ & $4.83 \%$ \\
\hline $2011 / 2012$ & $50,786,299$ & 47 & $7.12 \%$ & $4.71 \%$ \\
\hline $2012 / 2013$ & $49,177,263$ & 48 & $6.90 \%$ & $4.54 \%$ \\
\hline 2013/2014 & $49,645,356$ & 49 & $6.77 \%$ & $4.47 \%$ \\
\hline
\end{tabular}

25 times the original expected usage, indicating that in the service period the need for the crossing has been demonstrated and the opportunities provided by the crossing have led to behavior changes that have demonstrated increasing reliance on the crossing. Prior to 2005/2006 usage increased, and there has been some decline since. The growth in service demand led to construction of an additional tunnel, 1980, and a bridge, 1991. In addition to providing additional capacity the construction of additional elements of the crossing has changed profoundly the crossing resilience. So long as the disruptive events do not close simultaneously more than one of the crossing legs, traffic can use the other legs, avoiding additional journey distance and avoiding increasing congestion on the alternative routes, albeit, at the cost of increased congestion and consequent increased journey time on the remaining crossing leg, or legs.

The crossing is subject to four kinds of events which would show in a measure of resilience of the form of equation (1):

1) Events which slow traffic, thus reducing capacity and increasing journey time; 
2) Events, such as collisions, which cause a short-term closure at unpredictable times;

3) Emergency long-term closures caused by damage or discovery of a safety related need for repairs; and

4) Closures caused by major planned maintenance.

Type 1 and 2 events cause frustration and some loss to each of many stakeholders who intended to use the crossing but because of their short-term or delay-only effects are usually tolerated. If they are too frequent they may lead to calls to alleviate the problems. Type 3 and 4 disruptions have severe impact, particularly on regular users who have made arrangements that involve using the crossing for shipment of goods or commuting because they face an extended period during which their usual journeys will take longer. For commercial shippers, the additional time for using other routes could result in their existing fleet having insufficient capacity to perform their shipping need.

In the case of this crossing, the construction of additional facilities, rather than expanding the original facility has a direct benefit for resilience because of the provision of an adjacent alternative which can function independently. If capacity had been increased in a single, enlarged, facility the effect of events of any of the four kinds would be loss of service of the whole of the enlarged service.

If the original crossing had been expanded there would have been a long period of no service delivery during the up-grade. This problem was avoided by building additional facilities where disruption was limited to relatively short periods while the new element was connected to the existing road network.

Construction of separated facilities provides a system in which any event disrupts part of the service, as provided by the disrupted element, but the remaining elements can continue to either provide their normal service, or if there is dynamic reallocation of usage (such as a two lane one-direction roadway being switchable to a one lane each way roadway) enabled, service may be continued at a diminished quality using the elements not affected by the original disruptive event. The provision of increased capacity by parallel facilities, each able to provide useful service independently, is an example of an architectural approach which implements Jackson's "Functional Redundancy" design principle listed in [16][17] and derived from Leveson [18].

\section{System Scenario 4 - Factory}

\section{1) Description}

We consider now the industrial system of a factory. A factory comprises a combination of infrastructure, the structure of the facility, and the equipment which enables production. We consider two factory sub-scenarios: a factory for general purpose production of a class of product, for example cars; and a factory for production of specialized product in a rapidly changing technology field, for example a leading edge chip foundry.

\section{2) General Purpose Factory Manifestation of Resilience}

In the case of the general purpose factory there are two distinguishable parts, the factory infrastructure and the equipment directly used in production. The infrastructure aspect: the buildings, surrounding access spaces and the provisioning for the installation and sustainment of productive equipment is envisaged as a long-term investment in a facility which will be reconfigurable for production of related, but different, products, with potentially significant differences, over an extended period, probably decades. As such the buildings would be long-term depreciated assets, retaining, at least, significant operational value, and therefore need for resilience to environmental conditions on a decades time scale. The value of resilience of the factory infrastructure would be at least steady through life, and might increase if the role of the factory becomes more central to the operations of the company.

The machinery fit-out is designed based on having equipment capable of performing processes in the production of the product class, the need for which is expected to endure across a series of product models. Accommodation of the range of specific products is enabled through fitment of production tools to suit the specific design. Each machinery item would normally be separately replaceable in the factory. In this case the desirable timeframe of equipment resilience is long, across generations of product, with similar considerations applying as for the factory infrastructure. The resilience value characteristic is likely to be closer to Scenario 3, above, than the other scenarios.

\section{3) Cutting Edge Factory Manifestation of Resilience}

In the production of products in a rapidly evolving technology the producer has a short window in which to generate a return on investment, so the factory, both infrastructure and equipment, requires a high resilience through the period in which it is the most advanced available. This requires consideration of resilience with respect to continuity of all the factors required to keep it in service.

Since the field is subject to rapid evolution the factory could be kept in service, producing superseded classes of product, which have "commodity" product value but do not command the premium prices of the most advanced available generation. The result is that the economic value of factory resilience of the factory during this period declines. The value of resilience of the productive facilities $\mathrm{n}$ the factory is likely to follow a similar pattern to Scenario 2, above.

The value of resilience of the factory infrastructure depends on the extent to which changes in the manufacturing equipment that will enable production of new generations of product demand changes in the infrastructure which cannot be provisioned for at initial construction time, and the return on investment of any such forward speculations. Therefore, the value of resilience of the factory infrastructure is similar to the value of resilience in scenario 2 , above.

\section{CONCLUSION}

The purpose of this paper has been to investigate a corollary of Equation (1), first presented in [1], specifically the apparent analogy of Equation (1) to the well-known TVM relationships of engineering economics, Equation (2). Whilst there is an apparent analogy, the relationship is not direct. The TVM relationships provide a set of relationships involving the elements of present value, final value, interest rate and number of interest compounding intervals, which can be expressed as definite mathematical relationships. 
The time value of resilience is not so simply defined nor calculable. The concept of time value of resilience is built on the concept of resilience embedded in the measure of resilience presented and explained in the former paper [1]. To rehearse the background:

1) Products and systems are developed to provide service to stakeholders.

2) Products and systems provide performance in multiple dimensions.

3) Comparison of the relative desirability of two alternatives can be determined using decision analysis methods including weighting and a value-for-scale function for each dimension.

4) During the life of a product, or system, events occur which impair its performance.

5) The purpose of a product or system is to provide service through its life and the most desirable system alternative is the one which provides the greatest time integral of the alternative comparison through a large plurality of whole life cycles.

The reasoning described above is significantly different than other perspectives on the engineering of resilient systems because it recognizes, and accepts, that any engineered thing will confront a wide variety of circumstances through its life and that failures will occur, either through wear-out, inherent flaws, or external threats. Regardless of cause, events will lead to partial or complete impairment of the system. User stakeholders, in the various theoretical classes of user stakeholders are focused on the capacity of the system to provide sufficient service to enable, if possible, a close approximation of intended performance when the system is under duress, and if this is not possible, to manage systems performance when failures occur to provide planned levels of loss determined, during design to be reasonable in the event of the failures which occur. The stakeholders are interested in the management of the real effect of the system but are not interested in cause of failures.

In relation to the question addressed in this paper four cases were explored with the characteristics:

1) The product has a short useful life, and survival beyond that useful life is either not useful or even a disadvantage.

2) The product has a finite life through which platform resilience is useful and valuable to achieve through design. The finite duration for which platform resilience is valuable is linked to a finite interval through which mission resilience if valuable.

3) Failure of the system has growing impact, in terms of losses associated with system failure, through time. The effect of this growing impact of systems failure or diminishment shows that the value of resilience of the system increases with age of the system.

4) A fourth case in which two variants were identified which result in the case being best approximated by either the second or third cases in the preceding paragraphs.

The impact of the time value of resilience effect is that the desirable resilience capability of a system depends on the system context. This observation must result in design consideration being given to the time profile of the value of resilience. The time value of resilience may make achievement of resilience later in the life-cycle of greater value, either absolutely, or per unit of disruption, than failure early in the life-cycle. This situation is challenging to designers because, as the system ages, the elements of the system are, in most cases, more likely to fail because of wear-out effects, and possibly take longer to resolve because of obsolescence issues, but each such breakdown has an increasing cost to stakeholders.

In this paper we have shown that there is a meaningful concept of time value of resilience. This paper has not made any definitive finding concerning the specific mathematical description of the time value of resilience for any system or kind of system. The mathematical description of the time value of resilience is a subject for further research. The presentation of the four cases suggests that the time value of resilience formulae are likely to require case specific investigation to yield case specific time factors for each future year. The time value of resilience can be described by modifying Equation (1), according to the discussion in Section II.D, to reflect the possibility of time variance of each, or both, of the weighting factors and the value for scale functions, as Equation (5).

$$
\begin{aligned}
& F O M=\sum_{i=1}^{n} \sum_{j=0}^{m-1}\left(( w _ { i k } ( t ) ) \cdot ( ( v _ { i k } ( t ) ) ( P _ { i j } ) ) \cdot \left(t_{j+1}-\right.\right. \\
& \left.\left.t_{j}\right)\right)
\end{aligned}
$$

At the heuristic level of description, the nature of increasing or decreasing impact of failures at future dates has been established and quantification of the time value of resilience, necessary to meaningfully use the concept in the measurement of resilience construct of Equation (1), requires further research and appears likely to be specific to each system development.

\section{REFERENCES}

[1] T. L. J. Ferris, "A resilience measure to guide system design and management," IEEE Syst. J., vol. 13, no. 4, pp. 3708-3715, 2019.

[2] M. Heidegger, J. Macquarrie, and E. Robinson, Being and time. Oxford: Basil Blackwell, 1973.

[3] M. Heidegger and J. Stambaugh, On time and being. New York: Harper and Row, 1972.

[4] W. J. Fabrycky and B. S. Blanchard, Life-cycle cost and economic analysis. Englewood Cliffs, New Jersey: Prentice Hall, 1991.

[5] P. Marnell, Engineering economics for the 21st century. Hoboken, New Jersey: John Wiley and Sons, Inc., 2016.

[6] B. N. Budogo, G. I. Mnyone, and M. S. Juma, "Displacement of urban poor in Dodoma municipality: A case of two selected wards, Ng'ong'ona and Ntyuka, Central Tanzania," J. Soc. Sci. Res., vol. 4, no. 4, pp. 67-73, 2018

[7] R. D. Espinoza and J. Rojo, "Towards sustainable mining (part I): Valuing investment opportuinties in the mining sector," Resour. policy, vol. 52, pp. 7-18, 2017.

[8] R. D. Espinoza and J. W. F. Morris, "Towards sustainable mining (part II): Accounting for mine reclamation and post reclamation care liabilities," Resour. policy, vol. 52, pp. 29-38, 2017.

[9] M. L. de Peres, R. de Avila Delucis, D. A. Gatto, and R. Beltrame, "Mechanical behavior of wood species softened by microwave heating prior to bending," Eur. J. wood Prod., vol. 74, pp. 143-149, 2016.

[10] M. Ito, "Introduction: personal, portable, pedestrian," in Personal, portable, pedestrian mobile phones in Japanese life, M. Ito, D. Okabe, and M. Matsuda, Eds. Cambridge, Massachusetts, London, England: The MIT Press, 2005, pp. 1-16.

[11] "No Title," 2019. [Online]. Available: apple.com. [Accessed: 04-Sep2019]. 
[12] M. Jones, "iPhone History: Every generation in order from 2007-2019," 2019. [Online]. Available: https://historycooperative.org/the-history-ofthe-iphone. [Accessed: 04-Sep-2019].

[13] C. Small et al., "Engineered resilient system with value focused thinking," in 27th Annual INCOSE international symposium, 2017.

[14] "Dartford crossing," wikipedia, 2019. [Online]. Available: en.wikipedia.org/wiki/Dartford_Crossing. [Accessed: 05-Sep-2019].

[15] Highways Agency, "Highways Agency: Traffic flow," 2014. [Online]. Available:

https://web.archive.org/web/20140714112503/http://www .highways.gov.uk/our-road-network/managing-ourroads/improving-our-network/the-dartford-thurrock-rivercrossing/traffic-flow/. [Accessed: 05-Sep-2019].

[16] A. M. Madni and S. Jackson, "Toward a conceptual framework for resilience engineering," IEEE Syst. J., vol. 3, no. 2, pp. 181-191, 2009.

[17] S. Jackson, Architecting Resilient Systems: Accident Avoidance and Survival and Recovery from Disruptions. Hoboken, NJ, USA: John Wiley \& Sons, 2010.

[18] N. Leveson, N. Dulac, D. Zipkin, Cutcher-Gershenfeld, J. Carroll, and B. Barrett, "Engineering Resilience into a Safety-Critical System," in Resilience Engineering: Concepts and Precepts, E. Hollnagel, D. D. Woods, and N. Leveson, Eds. Aldershot, UK: Ashgate Publishing Limited, 2006.

[19] "System resilience," Guide to the Systems Engineering Body of Knowledge (SEBoK), v. 1.9, 2017. [Online]. Available: http://www.sebokwiki.org/wiki/System_Resilience\#Definition. [Accessed: 25-Jun-2018].

[20] A. J. Nuss, T. D. Blackburn, and A. Garstenauer, "Toward resilience as a tradable parameter during conceptual trade studies," IEEE Syst. J., vol. 12, no. 4, pp. 3393-3403, 2018.

[21] O. U. Rehman, M. J. Ryan, and M. Efatmaneshnik, "Future proofing process," in 27th Annual INCOSE international symposium, 2017.

[22] L. Bukowski, "System of systems dependability - Theoretical models and applications examples," Reliab. Eng. Syst. Saf., vol. 151, pp. 76-92, 2016.

[23] R. Francis and B. Bekera, "A metric and frameworks for resilience analysis of engineered and infrastructure systems," Reliab. Eng. Syst. Saf., vol. 121, pp. 90-103, 2014.

[24] O. Erol, D. Henry, and B. Sauser, "Exploring resilience measurement methodologies," in INCOSE international symposium, 2010.

[25] O. Erol, D. Henry, B. Sauser, and M. Mansouri, "Perspectives on measuring enterprise resilience," in IEEE International systems conference, 2010, pp. 587-592.

[26] D. Henry and J. E. Ramirez-Marquez, "A generic quantitative approach to resilience: a proposal," in 20th Annual International Symposium of the International Council on Systems Engineering, 2010.

[27] D. Henry and J. E. Ramirez-Marquez, "Generic metrics and quantitative approaches for system resilience as a function of time," Reliab. Eng. Syst. Saf., vol. 99, pp. 114-122, 2012.

[28] D. Henry and J. E. Ramirez-Marquez, "On the impacts of power outages during Hurricane Sandy - a resilience-based analysis," Syst. Eng., vol. 19, no. 1, pp. 59-75, 2016.

[29] J. P. G. Sterbenz, E. K. Cetinkaya, M. A. Hameed, A. Jabbar, S. Qian, and J. P. Rohrer, "Evaluation of network resilience, survivability, and disruption tolerance: analysis, topology generation, simulation, and experimentation," Telecommun. Syst., vol. 52, pp. 705-736, 2013.

[30] S. Y. Han, K. Marais, and D. DeLaurentis, "Evaluating system of systems resilience using interdependancy analysis," in IEEE international conference on systems, man, and cybernetics, 2012, pp. $1251-1256$.

[31] P. Uday and K. Marais, "Resilience-based system importance measures for system-of-systems," Procedia Comput. Sci., vol. 28, pp. 257-264, 2014.

[32] P. Uday and K. Marais, "Designing resilient systems-of-systems: a survey of metrics, methods, and challenges," Syst. Eng., vol. 18, no. 5, pp. 491-510, 2015.

[33] B. M. Ayyub, "Systems resilience for multihazard environments definition, metrics, and valuation for decision making," Risk Anal., vol. 34, no. 2, pp. 340-355, 2014.

[34] R. Raj et al., "Measuring the resilience of supply chain systems using a survival model," IEEE Syst. J., vol. 9, no. 2, pp. 377-381, 2015.

[35] C. Nan and G. Sansavini, "A quantitative method for assessing resilience of interdependent infrastructures," Reliab. Eng. Syst. Saf., vol. 157, pp. $35-53,2017$.

[36] H. T. Tran, M. Balchanos, J. C. Domercant, and D. N. Mavris, "A framework for the quantitative assessment of performance-based system resilience," Reliab. Eng. Syst. Saf., vol. 158, pp. 73-84, 2017.

[37] S. Hosseini, K. Barker, and J. E. Ramirez-Marquez, "A review of definitions and measures of system resilience," Reliab. Eng. Syst. Saf., vol. 145, pp. 47-61, 2016.

[38] C. on I. N. R. to D. H. and C. on S. E. and P. Policy, Disaster resilience: national imperative. Washington, DC: The National Academies Press, 2012.

[39] D. van der Beek and J. M. Schraagen, "ADAPTER: analysing and developing adaptability and performance in teams to enhance resilience," Reliab. Eng. Syst. Saf., vol. 141, pp. 33-44, 2015.

[40] J. Schneider, C. Romanowski, R. K. Raj, S. Mishra, and K. Stein, "Measurement of locality specific resilience an operational model," in IEEE international symposium on technologies for homeland security, 2015.

[41] B. E. Tokgoz and A. V Gheorghe, "Resilience quantification and its application to residential building subject to hurricane winds," Int. J. disaster risk Sci., vol. 4, no. 3, pp. 105-114, 2013.

[42] M. J. Wheaton and A. M. Madni, "Resiliency and affordability atributes in a system tradespace," in AIAA SPACE 2015 Conference and Exposition, AIAA SPACE Forum, (AIAA 2015-4434), 2015.

[43] A. M. Ross, D. H. Rhodes, and M. E. Fitzgerald, "Interactive value model trading for resilient systems decisions," in Procedia computer science Conference on systems engineering research, 2015, pp. 639648.

[44] J. S. Brtis, "How to think about resilience in a DoD context," Colorado Springs, CO, 2016.

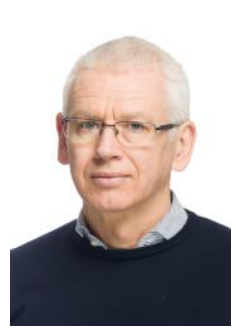

Timothy L.J. Ferris (M'91-SM'02) received the degrees B.E.Hons, University of Adelaide, 1982, B.Th., Flinders University, 1988, B.Litt.Hons., Deakin University, 1991, GradCertEd, Queensland University of Technology, 2002, and $\mathrm{PhD}$, University of South Australia, 1997. His $\mathrm{PhD}$ was in the theory of measurement.

$\mathrm{He}$ worked as an engineer for Electricity Trust of South Australia and Morrison Court Pty Ltd, and in the Presbyterian Church before commencing as a lecturer at University of South Australia, 1991. He is currently working in the Centre for Systems and Technology Management, Cranfield University, Defence Academy of the United Kingdom Shrivenham, UK. He has published about 150 papers in journals and conferences and various other items.

Dr Ferris was Secretary, IEEE South Australia Section (2004-2005), is an Associate Editor of IEEE Systems Journal, and was Publication Chair, SoSE 2014 conference. He is a member of INCOSE. 